\title{
Important roles of C-terminal residues in degradation of capsid protein of classical swine fever virus
}

Yuming Chen ${ }^{\dagger}$, Erpeng Zhu ${ }^{\dagger}$, Shuangqi Fan, Hongxing Ding, Shengming Ma, Mengjiao Zhu, Shaofeng Deng, Jinding Chen ${ }^{*}$ and Mingqiu Zhao*

\begin{abstract}
Background: Capsid (C) protein plays an important role in the replication of classical swine fever virus (CSFV). The ubiquitin proteasome system (UPS) involves in replication of many viruses via modulation of viral proteins. The relationship of CSFV with UPS is poorly understood and the impact of 265 proteasome on C protein has never been reported before.

Methods: In this study, fused C protein with an EGFP tag is expressed in PK-15 and 3D4/2 cells. MG132 and 3methyladenine (3-MA) are used to detect the roles of 265 proteasome and autophagolysosome in expression levels of $C$ protein. Truncated and mutant $C$ proteins are used to find the exact residues responsible for the degradation of $\mathrm{C}$ protein. Immunoprecipitaion is performed to find whether $\mathrm{C}$ protein is ubiquitinated or not.

Results: C-EGFP protein expresses in a cleaved form at a low level and is degraded by 265 proteasome which could be partly inhibited by MG132. C-terminal residues play more important roles in the degradation of C protein than N-terminal residues. Residues 260 to 267, especially M260 and L261, are crucial for the degradation. In addition, C-terminal residues 262 to 267 determine cleavage efficiency of $C$ protein.

Conclusions: CSFV C protein is degraded by 265 proteasome in a ubiquitin-independent manner. Last 8 residues at C-terminus of immature C protein play a major role in proteasomal degradation of CSFV C protein and determine the cleavage efficiency of $\mathrm{C}$ protein by signal peptide peptidase (SPP). Our findings provide valuable help for fully understanding degradation process of $\mathrm{C}$ protein and contribute to fully understanding the role of $\mathrm{C}$ protein in CSFV replication.
\end{abstract}

Keywords: Classical swine fever virus (CSFV), C protein, 26S proteasome, Degradation, Cleavage

\section{Background}

The ubiquitin proteasome system (UPS) is consist of the ubiquitin cascade reaction system and $26 \mathrm{~S}$ proteasome. The UPS and lysosome-dependent autophagy system are two major ways of protein degradation in cells and they play significant roles in various cell activities by modulation of key protein levels [1-5]. Ubiquitination is a kind of posttranslational protein modification in which ubiquitin is added to the substrate protein by covalent bonding [6]. Most proteins degraded by the $26 \mathrm{~S}$ proteasome are

\footnotetext{
* Correspondence: jdchen@scau.edu.cn; zmingqiu@scau.edu.cn ${ }^{\dagger}$ Yuming Chen and Erpeng Zhu contributed equally to this work. College of Veterinary Medicine, South China Agricultural University, No. 483, Wushan Road; Tianhe District, Guangzhou 510642, People's Republic of China
}

modified by ubiquitination, while some are degraded in a ubiquitin-independent manner with the involvement of proteasome activator 28 (PA28) or other proteins [7, 8]. Ubiquitination mostly occurs on lysine residues and sometimes on cysteine, serine, threonine, and tyrosine residues [9]. New insights about uiquitination are being discovered with more and more researches' focus.

Due to the close relationship of virus and host cell, many studies have shown that the UPS widely involves in virus infection and replication [10-12]. The UPS could modulate levels of viral proteins through ubiquitination and degradation $[10,11]$ and UPS may play complex roles during virus replication. On the one hand, degradation of viral proteins by the $26 \mathrm{~S}$ proteasome serves as a host 
defense strategy to eliminate extraneous antigens [8]. On the other hand, degradation of viral proteins, such as RNA dependent RNA polymerase ( $R d R p)$, has been demonstrated to interfere with viral packaging $[13,14]$, may increasing viral assembly efficiency and contributing to viral evasion of the host immune system.

Classical swine fever virus (CSFV) from Flaviviridae family is highly pathogenic to pigs and causes great economic losses in the pig industry worldwide [15]. Its genome contains a $12.3 \mathrm{~kb}$ positive-sense single-stranded RNA sequence with a single large open reading frame (ORF) which encodes a polyprotein precursor that could be cleaved by cellular and viral proteases to generate $12 \mathrm{sep}$ arate mature proteins $[16,17]$. Capsid $(C)$ protein encoding gene is located between viral gene $N^{p r o}$ and $E^{r n s}$ and is one of the four structural proteins. $\mathrm{C}$ protein forms by autocatalysis of the $\mathrm{N}^{\text {pro }}$ at the $\mathrm{N}$ terminus and the cleavage of cell signal peptidase (SP) at the $C$ terminus [18-20]. Besides, $\mathrm{C}$ protein is further cleaved by signal peptide peptidase (SPP) between residues A255/V256 to yield the mature $\mathrm{C}$ protein which contains 87 amino acids with a molecular weight (MW) about $14 \mathrm{kDa}$. SPP catalyzes intramembrane proteolysis of some signal peptides [21]. Heimann et al. found that CSFV C protein is easy to detect in concentrated virions but difficult to find in CSFV infected cells, which shows that $C$ protein is unstable in cells [21].

CSFV C protein is important for efficient viral replication via interactions with both viral proteins and cellular proteins [22]. It has been identified that $\mathrm{C}$ protein interacts with viral protein NS5B and enhances its RNA dependent RNA polymerase aitivity [23]. Besides, interactions of $\mathrm{C}$ protein with cellular proteins SUMO-1 (small ubiquitinlike modifier 1), UBC9 (a SUMO-1 conjugating enzyme) and IQGAP1 are crucial for efficient viral proliferation and viral virulence $[24,25]$. Interaction of $C$ protein with hemoglobin subunit beta $(\mathrm{HB})$ suppresses interferon- $\beta$ (IFN- $\beta$ ) production via RNA helicases retinoic acidinducible gene I (RIG-I) pathway by down-regulation of $\mathrm{HB}$, leading to immune suppression which is beneficial for persistent CSFV replication [26].

Hepatitis $\mathrm{C}$ virus (HCV) is in the same family with CSFV and viral proteins core, p7, NS2 and RdRp of $\mathrm{HCV}$ could all be degraded by $26 \mathrm{~S}$ proteasome, showing the close relationship of $\mathrm{HCV}$ and $26 \mathrm{~S}$ proteasome [2731]. Considering the close similarity of CSFV and HCV, the low level of $\mathrm{C}$ protein in CSFV infected cells, and that the relation of CSFV $C$ protein and UPS has not been explored yet, we try to reveal the impact of UPS on CSFV C protein and explore the mechanism.

\section{Materials and methods \\ Cells}

The porcine kidney cell line PK-15 (ATCC, CCL33) was grown in Dulbecco's modified Eagle's medium
(DMEM) supplemented with 10\% fetal bovine serum (FBS). Porcine macrophage cell line 3D4/2 (ATCC, CRL2845) was maintained in RPMI 1640 medium (11875093, Thermo Fisher Scientific) supplemented with 10\% FBS. Cells were cultured at $37^{\circ} \mathrm{C}$ in a $5 \% \mathrm{CO}_{2}$ incubator.

\section{Plasmids construction}

Plasmids pEGFP-N1-C and pEGFP-C1-C were constructed by cloning $\mathrm{C}$ protein-encoding gene of CSFV strain Shimen (GenBank accession no. AF092448.2) into pEGFP-N1 and pEGFP-C1 vectors (Clontech), respectively. Plasmid pEGFP-N1-C encodes C-EGFP protein fused with EGFP tag at C-terminal (Fig. 1c), and pEGFPC1-C encodes EGFP-C protein fused with EGFP tag at $\mathrm{N}$-terminal (Fig. 2b). A series of plasmids encoding truncated forms of $\mathrm{C}$ protein, $\mathrm{C}_{\Delta \mathrm{C}}, \mathrm{C}_{\Delta \mathrm{N}}, \mathrm{C}_{\Delta 8}, \mathrm{C}_{\Delta 7}, \mathrm{C}_{\Delta 5}$ and $\mathrm{C}_{\Delta 2}$ (Fig. 3a and $4 \mathrm{a}$ ), with various amino acid deletions were generated from pEGFP-N1-C by conventional PCR with the primers listed in Table 1 . The constructs encoding mutant forms of $\mathrm{C}$ protein, $\mathrm{C}_{\mathrm{M} 260-261}$ and $\mathrm{C}_{\mathrm{M} 260-263}$ (Fig. 5a), were generated by cloning the corresponding mutant sequences into pEGFP-N1 vector. All plasmids were verified by DNA sequencing to ensure that the target gene is in frame with the EGFP-coding sequence, with no intervening stop codons.

\section{Plasmids transfection}

At about $70 \%$ confluence, cells in 12-well plates cultured at $37^{\circ} \mathrm{C}$ in a humidified incubator with $5 \% \mathrm{CO}_{2}$ were transfected with the indicated plasmids (1.5 $\mu \mathrm{g}$ each) using Lipo6000 ${ }^{\mathrm{Tm}}$ transfection reagent (C0528, Beyotime) according to the manufacturer's instructions. At $4 \mathrm{~h}$ post-transfection (hpt), the transfection mixture was replaced with DMEM or drugs-containing DMEM supplemented with $2 \%$ FBS. Cells were collected at the indicated time points for the following Western blot analysis or were subjected to indirect immunofluorescence assay.

\section{Biochemical intervention}

PK-15 or 3D4/2 cells are treated with $10 \mu \mathrm{M}$ MG132 (A2585, Apexbio) diluted in dimethyl sulfoxide (DMSO) or 5 mM 3-methyladenine (3-MA) (A8353, Apexbio) diluted in sterile $\mathrm{dd}_{2} \mathrm{O}$ for $16 \mathrm{~h}$. The same amount of DMSO or $\mathrm{ddH}_{2} \mathrm{O}$ was added to the inoculum as controls.

\section{Quantitative real-time PCR}

Total RNA was extracted from cells and was then reverse transcribed to cDNA with Moloney murine leukemia virus reverse transcriptase $(2641 \mathrm{~A}, \mathrm{TaKaRa})$ according to the manufacturer's instructions. Gene expression was quantified by quantitative real-time polymerase chain reaction (qRT-PCR) with TB Green ${ }^{\circledR}$ Premix Ex Taq ${ }^{\text {TM }}$ II (RR820A, TaKaRa) in the CFX96 real-time PCR system (Bio-Rad). 


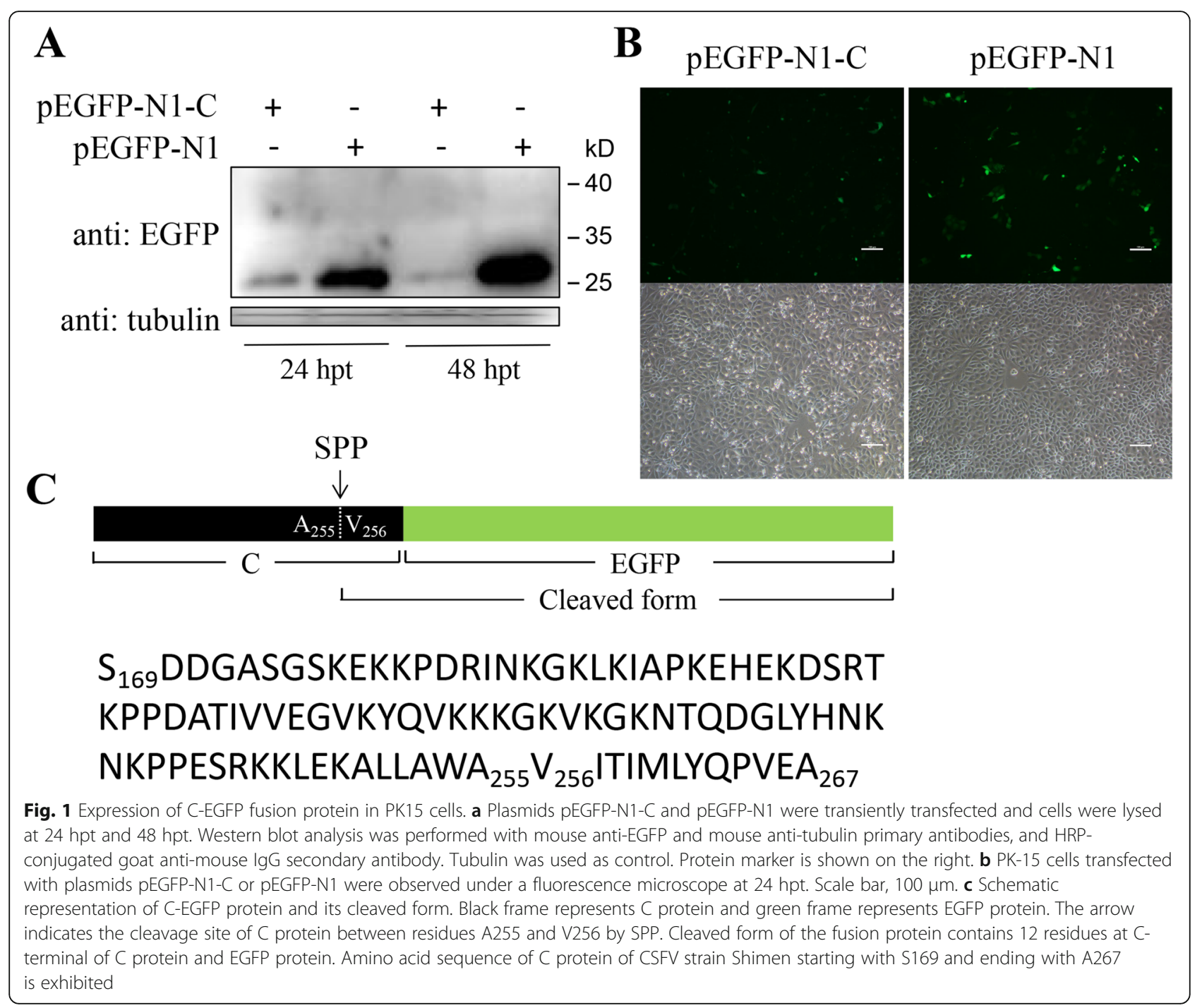

The primers used to detect EGFP, $\mathrm{C}$ and GAPDH are listed in Table 1 . The relative abundance of each target was obtained by normalization with endogenous GAPDH.

\section{Immunoprecipitation}

Immunoprecipitation was performed as previously described. Briefly, PK-15 cells transfected with the indicated plasmids were lysed, and the supernatants obtained by centrifuging were incubated with anti-EGFP antibody and protein A/G agarose (P2055, Beyotime) at $4{ }^{\circ} \mathrm{C}$ overnight. The beads were then rinsed with PBS and subjected to SDSPAGE. Protein bands were detected by Western blot using anti-EGFP and anti-Ub (sc-166,553, Santa) antibodies.

\section{Western blot analysis}

Protein samples obtained from cell lysates were mixed with $5 \times$ protein loading buffer, boiled at $100^{\circ} \mathrm{C}$ for $10 \mathrm{~min}$ and then subjected to SDS-PAGE. Proteins were separated and transferred to a PVDF membrane (Roche). The nonspecific antibody binding sites were blocked with 5\% skim milk in PBS-Tween (PBST). Membranes were incubated with mouse anti-EGFP (AG281, Beyotime) (1:2000) or mouse anti-tubulin (AT819, Beyotime) (1: 2000) primary antibodies diluted in PBS at $4{ }^{\circ} \mathrm{C}$ overnight, and then incubated with $\mathrm{HRP}$-conjugated goat anti-mouse IgG secondary antibody diluted in PBS (1: 1000) at $37^{\circ} \mathrm{C}$ for $1 \mathrm{~h}$. The signals were detected using an ECL imaging system. The images were obtained from a CanoScan LiDE 100 scanner (Canon) and quantities of protein blots were measured with Image J software.

\section{Results}

C-EGFP fusion protein expresses in a cleaved form in PK15 cells

To explore the expression characteristics of exogenous $\mathrm{C}$ protein, recombinant plasmid pEGFP-N1-C was transfected in PK-15 cells. Empty vector pEGFP-N1 was transfected as a control. Western blot analysis of 

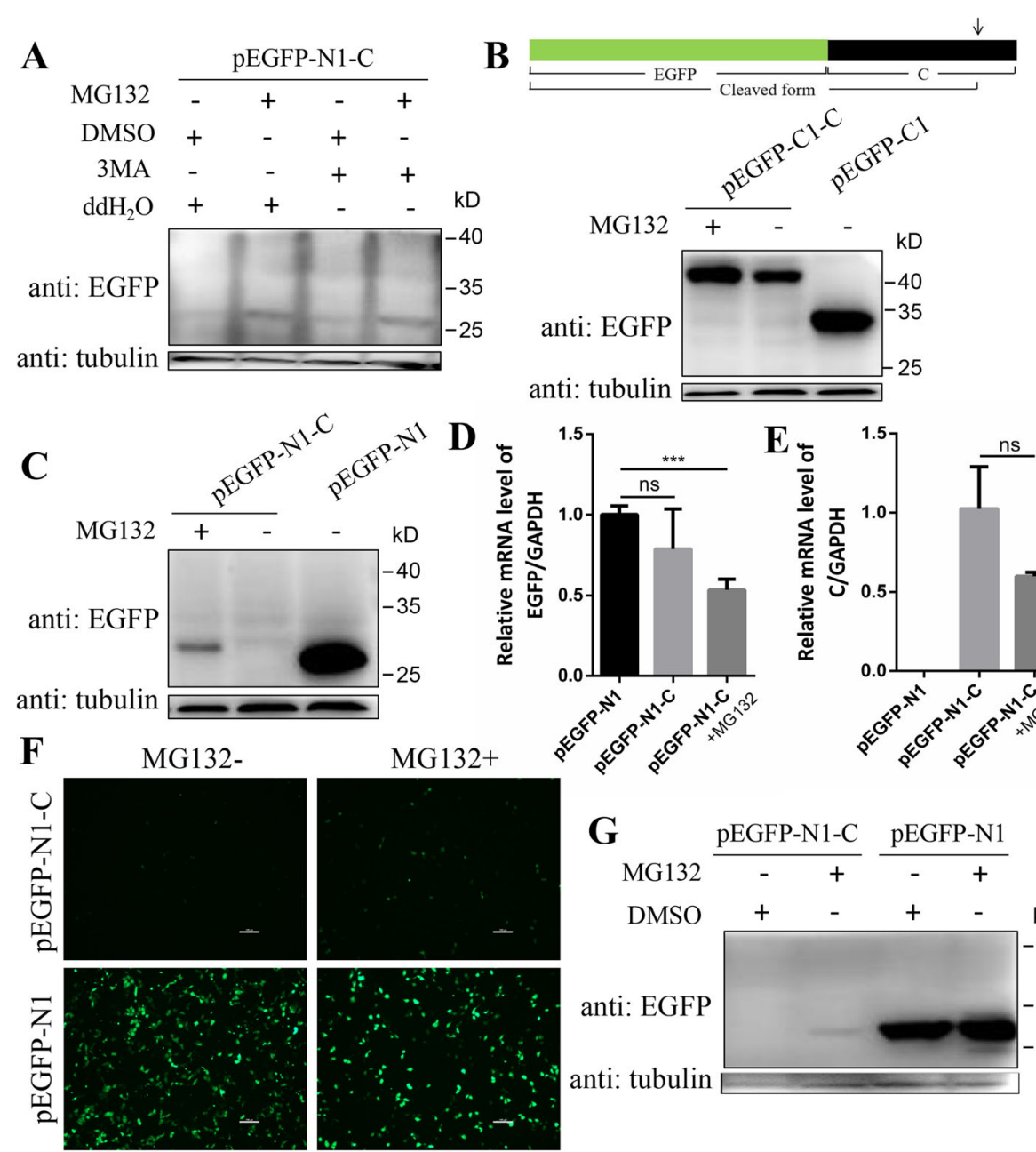

D
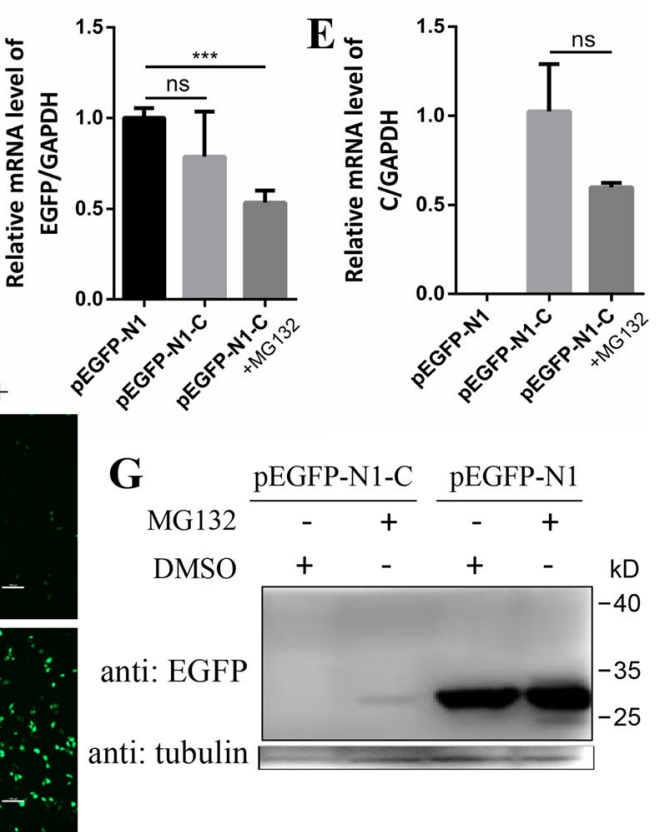

Fig. 2 MG132 upregulated the level of EGFP-tagged C protein. a PK-15 cells were transfected with plasmid pEGFP-N1-C followed by treatment of $10 \mu \mathrm{M}$ MG132 or $5 \mathrm{mM} 3-\mathrm{MA}$ or both of them for $16 \mathrm{~h}$. DMSO or dd $\mathrm{H}_{2} \mathrm{O}$ were used as controls. At $20 \mathrm{hpt}$, cells were lysed and subjected to Western blot analysis with the indicated antibodies. Tubulin was used as a control. b Schematic representation of EGFP-C protein and its cleaved form. Black frame represents C protein and green frame represents EGFP protein. The arrow indicates the cleavage site of C protein by SPP. PK-15 cells were transfected with plasmid pEGFP-C1-C and were treated with or without MG132 (10 MM). Empty vector pEGFP-C1 was used as a control. Cells were lysed at $20 \mathrm{hpt}$ and Western blot was performed with the indicated antibodies. c PK-15 cells were transfected with plasmid pEGFP-N1$\mathrm{C}$ and treated with or without MG132 as described above. Empty vector pEGFP-N1 was used as a control. Western blot was performed as described above. Relative mRNA levels of EGFP (d) and C (e) in cells were detected by qRT-PCR. Data was analyzed by Student's t-test. $\mathbf{f} 3 \mathrm{D} 4 / 2$ cells were transfected with plasmid pEGFP-N1-C or PEGFP-N1 followed by treatment of $10 \mu \mathrm{M} \mathrm{MG132}$ or same volume of DMSO for $16 \mathrm{~h}$. The fluorescence in cells was observed at 20 hpt. Scale bar, $100 \mu \mathrm{m}$. g Cells in (f) were then lysed and analysed by Western blot with the indicated antibodies. Protein marker is shown on the right. Data in all bar plots are shown as mean \pm SD and representative of 3 biological replicates. ${ }^{* * *}$, $P<0.001 ;$ ns, not significant

samples from plasmid-transfected cells showed that no putative C-EGFP fusion protein band was detected at the expected position $(27+14 \mathrm{kD})$ at $24 \mathrm{hpt}$ and 48 hpt, while a weak band with a molecular weight (MW) close to EGFP tag (27 kD) was detected (Fig. 1a). Since $\mathrm{C}$ protein was previously reported to be cleaved between residues A255 and V256 by SPP, we assumed that C-EGFP fusion protein was possibly cleaved to generate an $\mathrm{N}$-terminal fragment with 87 amino acids and a C-terminal fragment with 12 residues fused to the EGFP tag (termed as cleaved form below) (Fig. 1c). Therefore, the protein bands in four panels have a similar molecular weight. Besides, cleaved C-EGFP protein expressed at a very low level compared with EGFP protein and less cleaved C-EGFP protein was detected at 48 hpt than 24 hpt (Fig. 1a), showing that $\mathrm{C}$ protein may be degraded after expression. The fluorescence result also showed that much less fluorescent signal was observed in cells transfected with pEGFP-N1-C than pEGFP-N1 (Fig. 1b). 


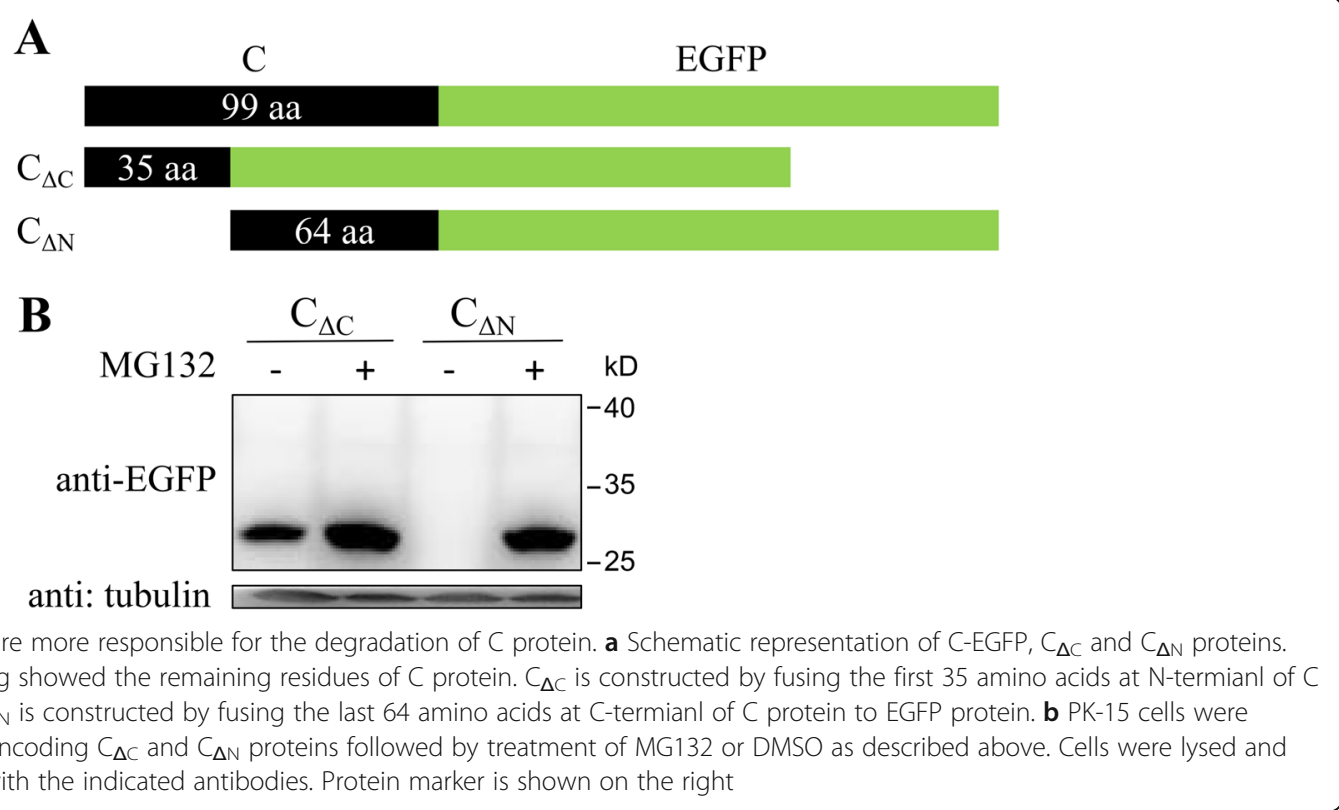

\section{C protein is degraded by $26 \mathrm{~S}$ proteasome}

Considering that C-EGFP protein expressed at a low level and decreased over time, we assume that C-EGFP protein might be degraded after expression. Since degradation of intracellular proteins are generally mediated by $26 \mathrm{~S}$ proteasome and autophagolysosome, we added inhibitors, MG132 and 3-MA, of them to the cell medium, respectively, after plasmid transfection. MG132 is commonly used in experiments about degradation of proteins by $26 \mathrm{~S}$ proteasome. Results showed that MG132 increased protein level of cleaved C-EGFP in PK-15 and 3-MA had no effect on protein level of cleaved C-EGFP (Fig. 2a). To examine whether the 87 residues at $\mathrm{N}$-terminal were affected by $26 \mathrm{~S}$ proteasome or not, plasmid pEGFP-C1-C encoding EGFP tagged $\mathrm{C}$ protein at $\mathrm{N}$-terminal, EGFP-C (Fig. 2b), was constructed and transfected in PK-15 cells. EGFP-C protein could be detected and MG132 upregulated its level (Fig. 2b), showing that the 87 residues at $\mathrm{N}$-terminal may be less affected by $26 \mathrm{~S}$ proteasome than the 12 residues at $\mathrm{C}$-terminal. Plasmids pEGFP-N1-C and pEGFP-N1 were transfected in PK-15 cells, respectively. Western blot results showed that cleaved form of C-EGFP protein expressed at a relatively low level compared with EGFP protein (Fig. 2c). Transcription levels of EGFP and $\mathrm{C}$ were analysed by qRT-PCR and the result showed that MG132 down-regulated average mRNA level of both EGFP (Fig. 2c-d) compared with the untreated group, though the impact of MG132 on mRNA level of $C$ was not significant. Although MG132 has opposite functions on mRNA and protein level of $\mathrm{C}$ protein, the conclusion that MG132 up-regulated protein level of $C$ protein could also be obtained. Similar results were observed in 3D4/2 cells, that MG132 up-regulated the level of C-EGFP protein (Fig. 2f) and fluorescence intensity (Fig. 2g). Since protein level of EGFP was not upregulated by MG132 (Fig. $2 \mathrm{~g}$ ), we concluded that $\mathrm{C}$ protein was the target of $26 \mathrm{~S}$ proteasome.

\section{C-terminal residues are more important for the degradation of $\mathrm{C}$ protein}

To reveal the degradation details of $\mathrm{C}$ protein, two truncated $\mathrm{C}$ proteins with $\mathrm{N}$ - or $\mathrm{C}$-terminal residues deletion were designed (Fig. 3a) and expressed in PK-15 cells. $\mathrm{C}_{\Delta \mathrm{C}}$ was detectable and MG132 up-regulated its protein level (Fig. 3b). $C_{\Delta N}$ was not detectable and MG132 upregulated its protein level, too (Fig. $3 \mathrm{~b}$ ). These results showed that protein levels of both $\mathrm{C}_{\Delta \mathrm{C}}$ and $\mathrm{C}_{\Delta \mathrm{N}}$ were regulated by $26 \mathrm{~S}$ proteasome. Comparing protein levels of $C_{\Delta C}$ and $C_{\Delta N}$ without MG132, it seemed that $C_{\Delta N}$ was more easily affected by $26 \mathrm{~S}$ proteasome, showing the greater effect of $\mathrm{C}$-terminal residues on the degradation of $\mathrm{C}$ protein.

\section{Determination of residues responsible for the degradation of $\mathrm{C}$ protein}

To further confirm the exact residues critical for the degradation of $C$ protein, a series of truncated proteins with various amino acid deletions at $\mathrm{C}$-terminal of $\mathrm{C}$ protein were designed and expressed in PK-15 cells (Fig. 4a). Results showed that expression of $\mathrm{C}_{\Delta 8}$ protein was apparently detectable compared with $C_{\Delta 7}$ (weak expression), $\mathrm{C}_{\Delta 5}$ (no expression) and $\mathrm{C}_{\Delta 2}$ (no expression) in the absence of MG132 (Fig. 4c). Therefore, the three different residues, M260, L261 and Y262, between $C_{\Delta 8}$ and $C_{\Delta 5}$ seemed critical for the degradation of C protein. MG132 


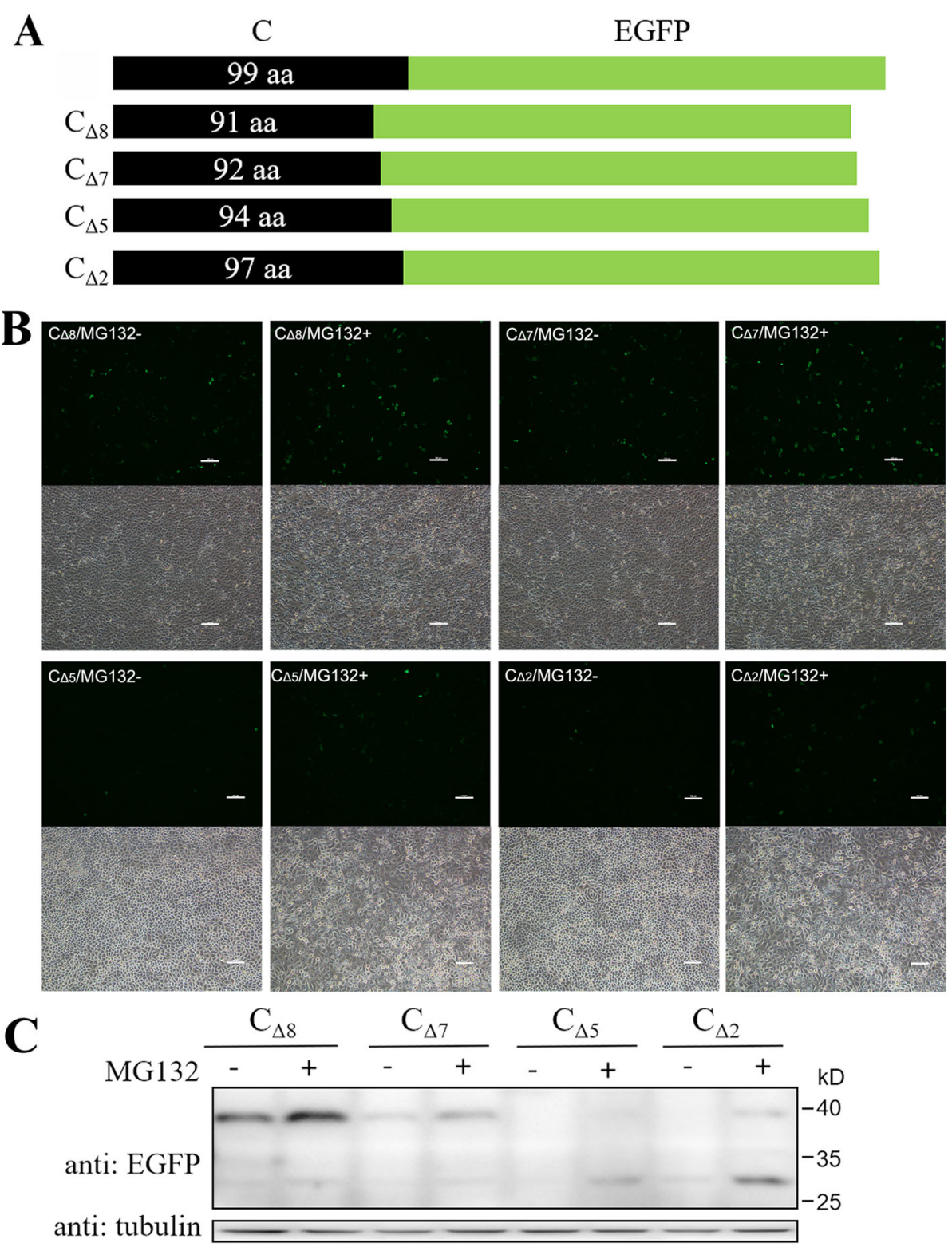

Fig. 4 C-terminal residues 260 to 267, especially 260-262, are responsible for the degradation of C protein. a Schematic representation of a series of truncated fusion proteins with various residues deletions at $C$-terminal of $C$ proteins. The numbers in dark oblong showed the remaining residues of $C$ protein. $\mathbf{b}$ PK-15 cells were transfected with plasmids encoding $C_{\Delta 8}, C_{\Delta 7}, C_{\Delta 5}$ and $C_{2}$ proteins, respectively. Cells were treated with MG132 or DMSO for $16 \mathrm{~h}$ and observed under a fluorescence microscope. Scale bar, $100 \mu \mathrm{m}$. c Cells were then lysed and analysed by Western blot with the indicated antibodies. Protein marker is shown on the right

increased the quantities of both immature and cleaved forms of $\mathrm{C}_{\Delta 8}, \mathrm{C}_{\Delta 7}, \mathrm{C}_{\Delta 5}$ and $\mathrm{C}_{\Delta 2}$ (Fig. 4c), showing that all these proteins were modulated by $26 \mathrm{~S}$ proteasome. Besides, MG132 up-regulated fluorescence intensity in cells expressing $\mathrm{C}_{\Delta 8}, \mathrm{C}_{\Delta 7}, \mathrm{C}_{\Delta 5}$ and $\mathrm{C}_{\Delta 2}$ (Fig. 4b).

\section{Residue mutations of M260A and L261 A partly inhibit C protein degradation}

To further confirm the roles of residues M260, L261 and Y262 in the degradation of $\mathrm{C}$ protein, site-directed mutagenesis-based study was conducted. Two mutant proteins, $\mathrm{C}_{\mathrm{M} 260-261}$ in which amino acid residues 260 and 261 were mutated to Alanine (A) and $\mathrm{C}_{\mathrm{M} 260-263}$ in which amino acid residues 260 to 263 were mutated to Alanine (A), were designed (Fig. 5a) and expressed in cells. Results showed that both $\mathrm{C}_{\mathrm{M} 260-261}$ and $\mathrm{C}_{\mathrm{M} 260-}$ 263 could be detected in full length without MG132 (Fig. 5b), confirming that M260 and L261 constituted the minimum domain that was responsible for the degradation of $\mathrm{C}$ protein via $26 \mathrm{~S}$ proteasome. 
Table 1 Primers used in this study

\begin{tabular}{|c|c|c|}
\hline Primer & Sequence $\left(5^{\prime}-3^{\prime}\right)$ & Use \\
\hline$C-F$ & GTACTCGAGATGTCTGATGATGGCGCA & Amplification of $C_{1}, C_{\Delta C}, C_{\Delta 8}, C_{\Delta 7}, C_{\Delta 5}$ and $C_{\Delta 2}$ \\
\hline$C_{\Delta N-F}$ & TACTCGAGATGCCACCCGACGCT & Amplification of $C_{\Delta N}$ \\
\hline$C-R$ & ATGGATCCCGGGCTTCAACTGGTT & Amplification of $C$ and $C_{\Delta N}$ \\
\hline$C_{\Delta C}-R$ & ATGGATCCCGCTTAGTTCTGCTGTC & Amplification of $C_{\Delta C}$ \\
\hline$C_{\Delta 8}-R$ & CGGATCCCGAATTGTTATTACCGC & Amplification of $\mathrm{C}_{\Delta 8}$ \\
\hline$C_{\Delta 7^{-}} R$ & CGGATCCCGCATAATTGTTATTAC & Amplification of $C_{\Delta 7}$ \\
\hline$C_{\Delta 5}-R$ & CGGATCCCGATACAACATAATTGT & Amplification of $C_{\Delta 5}$ \\
\hline$C_{\Delta 2}-R$ & CGGATCCCGAACTGGTTGATACAA & Amplification of $C_{\Delta 2}$ \\
\hline qPCR-EGFP-F & ATGGCCGACAAGCAGAAGAA & qRT-PCR for detection of EGFP \\
\hline qPCR-EGFP-R & AACTCCAGCAGGACCATGTG & \\
\hline qPCR-C-F & ACAGCAGAACTAAGCCACCC & qRT-PCR for detection of $C$ \\
\hline qPCR-C-R & TCTTGTTGTGGTACAGGCCG & \\
\hline qPCR-GAPDH-F & GAAGGTCGGAGTGAACGGATTT & qRT-PCR for detection of GAPDH \\
\hline qPCR-GAPDH-R & TGGGTGGAATCATACTGGAACA & \\
\hline
\end{tabular}

\section{CSFV C protein is not ubiquitinated}

To investigate whether degradation of $\mathrm{C}$ protein is ubiquitin dependent, proteins $\mathrm{C}_{\Delta 2}$ and $\mathrm{C}_{\mathrm{M} 260-263}$ were expressed in cells with MG132. EGFP was expressed as a control. Immunoprecipitation was performed and ubiquitin was detected by Western blot. Results showed that proteins $C_{\Delta 2}, C_{M 260-263}$ and EGFP were pulled down (Fig. 6). Unexpectedly, ubiquitin level in $C_{\Delta 2}$ and $\mathrm{C}_{\mathrm{M} 260-263}$ panels were even lower than the EGFP panel
(Fig. 6), indicating that degradation of $\mathrm{C}$ protein is not ubiquitin dependent.

\section{Discussion}

PK-15 and 3D4/2 are two cell lines that have a wide variety of applications in porcine virology studies [32-34]. In this study, C-EGFP fusion protein with EGFP tag at $\mathrm{C}$-terminal was not detected at the predicted position and cleaved C-EGFP protein was detected at the position

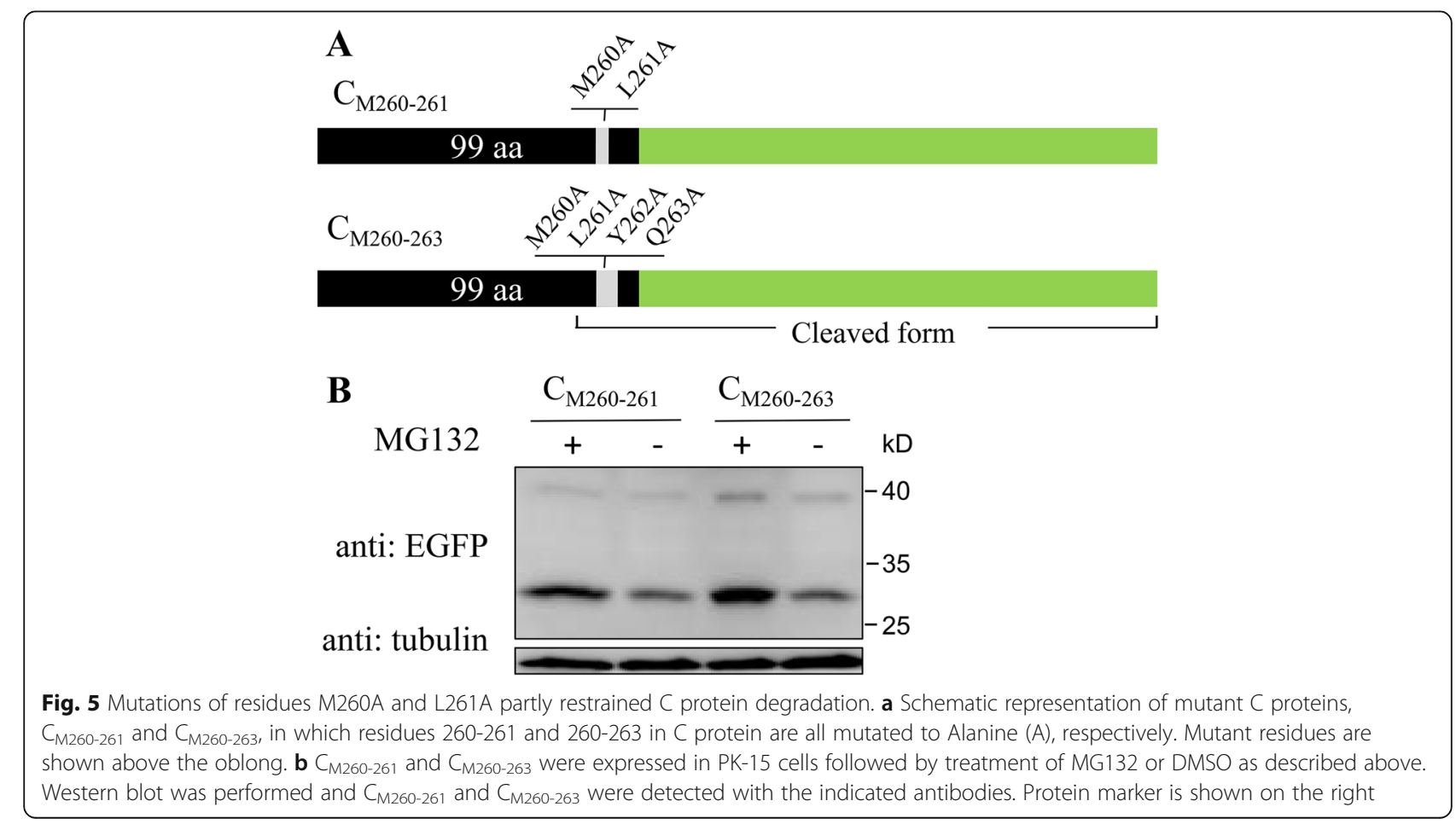




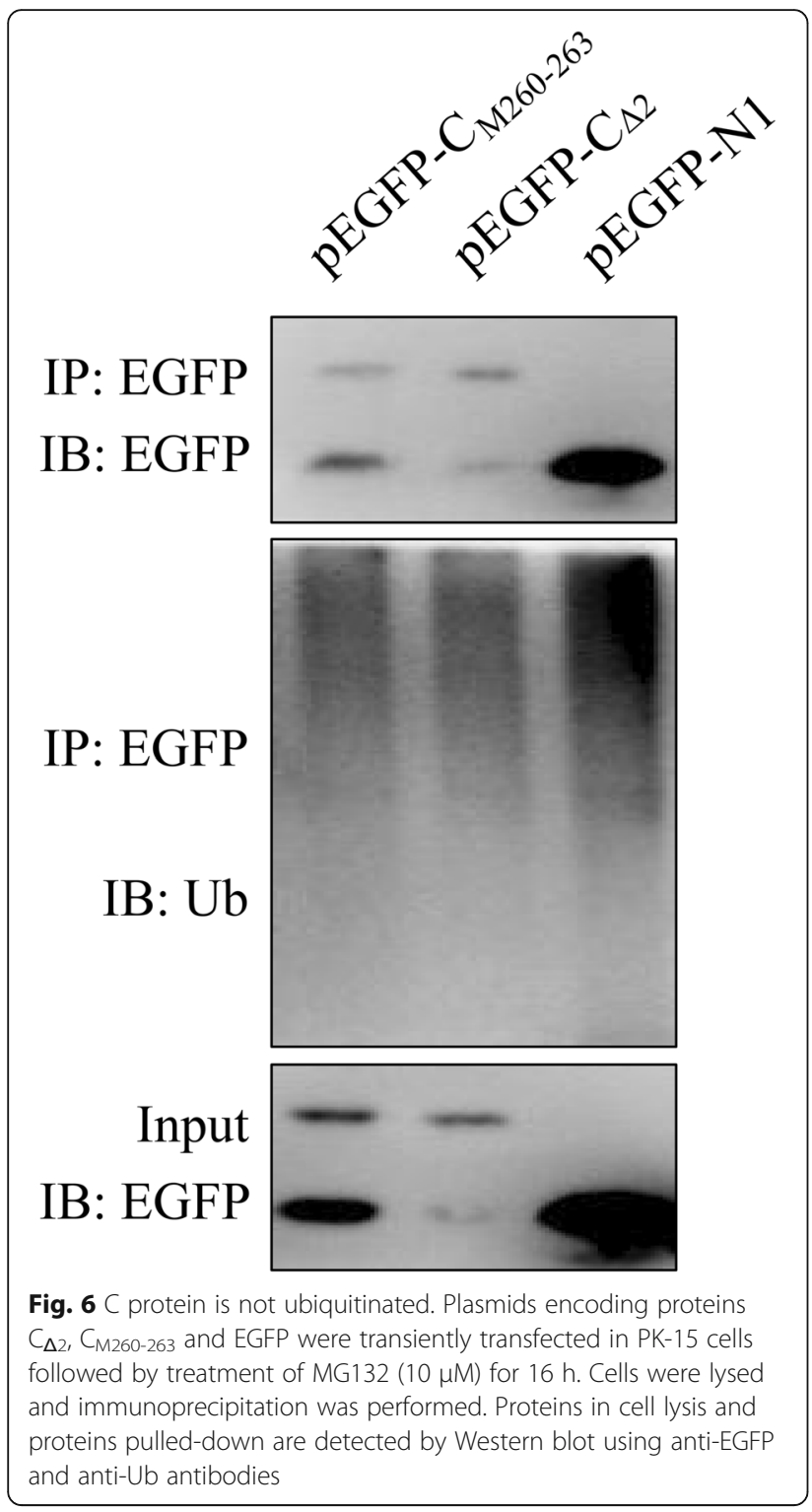

with a molecular weight close to EGFP tag (Fig. 2a). EGFP-C protein fused with EGFP tag at N-terminal was detected at the predicted position (Fig. 2b). MG132 upregulated protein levels of immature or cleaved forms of C-EGFP, EGFP-C and truncated $C$ proteins $\left(C_{\Delta \mathrm{C}}, \mathrm{C}_{\Delta \mathrm{N}}\right.$, $C_{\Delta 8}, C_{\Delta 7}, C_{\Delta 5}$ and $C_{\Delta 2}$ ), showing the strong and extensive effect of $26 \mathrm{~S}$ proteasome on the degradation of $\mathrm{C}$ protein. In a study about the cleavage of $\mathrm{C}$ protein, Heimann et al. found that CSFV C protein is difficult to detect in CSFV infected cells. Consistent with this finding, we find that small tagged $\mathrm{C}$ protein (HA or Flag tag) is hardly to detect in PK-15 cells, so we use the big EGFP tag in this study. And the results show that EGFP-tagged $\mathrm{C}$ protein could express at a low level. Taken together, the fusion protein was indeed cleaved in cells and EGFP tag prevents $\mathrm{C}$ protein from degrading to some extent.
This may be because that $C$ protein with a big tag covers part of the residues critical for the recognition of $\mathrm{C}$ protein by $26 \mathrm{~S}$ proteasome.

Apart from degradation, we also observed changes in cleavage of $\mathrm{C}$ protein by SPP in expressions of truncated $\mathrm{C}$ proteins. Since CSFV C protein has previously been identified to be cleaved between residues A255 and V256, truncated $C$ proteins containing this site are considered to be cleaved. In this study, $C_{\Delta 8}$ and $C_{\Delta 7}$ expressed mainly in uncleaved form (Fig. 4c), while $\mathrm{C}_{\Delta 5}$, $\mathrm{C}_{\Delta 2}, \mathrm{C}_{\mathrm{M} 260-261}$ and $\mathrm{C}_{\mathrm{M} 260-263}$ expressed mainly in cleaved form (Fig. 4c and 5b). While the SPP recognition site in C protein is from E248 to A267 [35], we conclude according to the results in this study that the last 6 residues (262 to 267) are extremely critical for the cleavage. By comparing expressions of $\mathrm{C}_{\Delta 8}, \mathrm{C}_{\Delta 7}, \mathrm{C}_{\Delta 5}$ and $\mathrm{C}_{\Delta 2}$, we further conclude that cleavage efficiency increased when there are more residues at C-terminal. Since cleavage efficiency is modulated by the last 6 residues (262 to 267) and degradation of $\mathrm{C}$ protein is larged determined by the last 8 residues (260 to 267), the last several residues seem to play dual functions in the process of $\mathrm{C}$ protein. Cleavage helps to eliminate the $26 \mathrm{~S}$ proteasome recognition site which plays a major role in $\mathrm{C}$ protein degradation, increasing $\mathrm{C}$ protein quantity. However, since $\mathrm{N}$ terminal also has partial effect on $\mathrm{C}$ protein degradation (Fig. 3), cleavage only partially inhibits $C$ protein degradation. Strong degradation of viral protein by $26 \mathrm{~S}$ proteasome may be a method employed by the host to restrict virus replication, a mechanism that has been identified in HCV, tomato bushy stunt virus (TBSV) and other viruses $[8,36,37]$.

Proliferation of CSFV is widely modulated by host cellular proteins [22]. CSFV C protein has been reported to interact with the osteosarcoma amplified 9 protein (OS9) [38], a glycoprotein located in endoplasmic reticulum (ER) which plays a role in the degradation of unfolded proteins [39]. Interestingly, OS9 interacts only with the immature form of CSFV $\mathrm{C}$ protein and the interaction is mediated by the last 12 residues at $\mathrm{C}$ terminal of $\mathrm{C}$ protein. Recombinant CSFV containing $\mathrm{C}$ protein lacking the ability to interact with OS9 showed a significantly decreased ability to replicate in cell cultures compared with the parental virus [38]. Though $C$ protein exists in viron only in mature form and residues 179 to 180, 194 to 198 , and 208 to 212 are identified significant for generation of progeny virus [40], immature C protein and its $\mathrm{C}$-terminal residues seem also play important roles in CSFV replication. Since OS9 also regulates protein degradation, whether OS9 plays a role in degradation of CSFV $\mathrm{C}$ protein needs further investigation.

Degradation and cleavage of core protein of $\mathrm{HCV}$, which is in the same faimly with CSFV, are revealed previously in several studies. Core protein of $\mathrm{HCV}$ could be 
degraded by $26 \mathrm{~S}$ proteasome in both ubiquitin-dependent and -independent proteasomal pathways [8]. Maturation of HCV immature core protein by SPP helps to promote viral proliferation efficiency and inhibition of maturation process causes endoplasmic reticulum stress which could be restricted by TRC8-dependent proteasomal degradation of immature core protein [31]. Similar to HCV C protein, degradation and cleavage of CSFV C protein may be two independent processes that play contrary roles in the modulation of level of $\mathrm{C}$ protein. In the counteract between host and CSFV, 26S proteasome might be employed by the host to decrease the level of viral $C$ protein and SPP might be utilized by CSFV to ensure enough mature $\mathrm{C}$ protein for replication. Considering the widely modulation roles of $26 \mathrm{~S}$ proteasome on cell activities, the role of degradation of $\mathrm{C}$ protein in CSFV replication needs further detailed investigation.

\section{Conclusions}

In this study, we identify for the first time the impact of $26 \mathrm{~S}$ proteasome on $\mathrm{C}$ protein of CSFV. C protein is degraded by $26 \mathrm{~S}$ proteasome, which could be partially inhibited by MG132. Though degradation of $C$ protein is regulated by different parts, $\mathrm{C}$-terminal residues seem more responsible than $\mathrm{N}$-terminal residues. $\mathrm{C}$-terminal amino acids, especially residues 262 to 267 , are crucial for the cleavage of $C$ protein by SPP. These results provide valuable reference for elucidating the mechanism underlying the degradation and maturation of CSFV C protein, and bring new insights into better understanding the biological processes of $\mathrm{C}$ protein of CSFV.

\begin{abstract}
Abbreviations
3-MA: 3-methyladenine; C: Capsid; CSF: Classical swine fever; CSFV: Classical swine fever virus; DMEM: Dulbecco's modified Eagle's medium; DMSO: Dimethyl sulfoxide; ER: Endoplasmic reticulum; FBS: Fetal bovine serum; HB: Hemoglobin subunit beta; HCV: Hepatitis C virus; hpt: hours posttransfection; IFN- $\beta$ : Interferon- $\beta$; MW: Molecular weight; ORF: Open reading frame; OS9: Osteosarcoma amplified 9; PA28: Proteasome activator 28; qRTPCR: quantitative real-time polymerase chain reaction; RdRp: RNA dependent RNA polymerase; RIG-I: RNA helicases retinoic acid-inducible gene I; SP: Signal peptidase; SPP: signal peptide peptidase; SUMO-1: Small ubiquitinlike modifier 1; TBSV: Tomato bushy stunt virus; UBC9: Ubiquitin-conjugating enzyme 9; UPS: Ubiquitin proteasome system
\end{abstract}

\section{Acknowledgments}

Not applicable.

\section{Authors' contributions}

YMC and EPZ contributed equally to this work; they designed this study, carried out Western blot analysis and drafted the manuscript; SQF and HXD cultured PK-15 cells, took fluorescent photographs and performed biochemical intervention experiments; YMC, SMM and MJZ constructed all the plasmids; SFD cultured 3D4/2 cells and took fluorescent photographs; as the corresponding author of this study, JDC and MQZ participated in the design of the study and revised the manuscript. All authors read and approved this version to be published.

\section{Funding}

This work was supported by grants of National Key R\&D Projects (No. 2017YFD0501104), Natural Science Foundation of China (No. 31672590) and Science and Technology Program of Guangzhou (No. 201803020005).

\section{Availability of data and materials}

The data supporting the findings in the current study are available from the corresponding author or the first author on reasonable request.

Ethics approval and consent to participate

Not applicable.

\section{Consent for publication}

All authors agreed the publication of this manuscript.

\section{Competing interests}

The authors declare that they have no competing interests.

Received: 30 July 2019 Accepted: 3 October 2019

Published online: 06 November 2019

\section{References}

1. Teixeira LK, Reed SI. Ubiquitin ligases and cell cycle control. Annu Rev Biochem. 2013;82:387-414.

2. Bednash JS, Mallampalli RK. Regulation of inflammasomes by ubiquitination. Cell Mol Immunol. 2016;13:722-8.

3. Gilberto S, Peter M. Dynamic ubiquitin signaling in cell cycle regulation. J Cell Biol. 2017;216:2259-71.

4. Martins-Marques T, Ribeiro-Rodrigues T, Pereira P, Codogno P, Girao H. Autophagy and ubiquitination in cardiovascular diseases. DNA Cell Biol. 2015;34:243-51.

5. Yu L, Chen Y, Tooze SA. Autophagy pathway: cellular and molecular mechanisms. Autophagy. 2018;14:207-15.

6. Grice GL, Nathan JA. The recognition of ubiquitinated proteins by the proteasome. Cell Mol Life Sci. 2016;73:3497-506.

7. Mao I, Liu J, Li X, Luo H. REGgamma, a proteasome activator and beyond? Cell Mol Life Sci. 2008;65:3971-80.

8. Suzuki R, Moriishi K, Fukuda K, Shirakura M, Ishii K, Shoji I, Wakita T, Miyamura T, Matsuura Y, Suzuki T. Proteasomal turnover of hepatitis C virus core protein is regulated by two distinct mechanisms: a ubiquitindependent mechanism and a ubiquitin-independent but PA28gammadependent mechanism. J Virol. 2009;83:2389-92.

9. McDowell GS, Philpott A. Non-canonical ubiquitylation: mechanisms and consequences. Int J Biochem Cell Biol. 2013;45:1833-42.

10. Luo H. Interplay between the virus and the ubiquitin-proteasome system: molecular mechanism of viral pathogenesis. Curr Opin Virol. 2016;17:1-10.

11. Isaacson MK, Ploegh HL. Ubiquitination, ubiquitin-like modifiers, and deubiquitination in viral infection. Cell Host Microbe. 2009;5:559-70.

12. Rajsbaum R, Garcia-Sastre A. Viral evasion mechanisms of early antiviral responses involving regulation of ubiquitin pathways. Trends Microbiol. 2013:21:421-9.

13. Kerkvliet J, Zoecklein L, Papke L, Denic A, Bieber AJ, Pease LR, David CS, Rodriguez M. Transgenic expression of the 3D polymerase inhibits Theiler's virus infection and demyelination. J Virol. 2009:83:12279-89.

14. Kerkvliet J, Papke L, Rodriguez M. Antiviral effects of a transgenic RNAdependent RNA polymerase. J Virol. 2011;85:621-5.

15. Paton DJ, Greiser-Wilke I. Classical swine fever--an update. Res Vet Sci. 2003; 75:169-78.

16. Thiel HJ, Stark R, Weiland E, Rumenapf T, Meyers G. Hog cholera virus: molecular composition of virions from a pestivirus. J Virol. 1991;65:4705-12.

17. Meyers G, Thiel HJ. Molecular characterization of pestiviruses. Adv Virus Res. 1996:47:53-118.

18. Rumenapf T, Unger G, Strauss JH, Thiel HJ. Processing of the envelope glycoproteins of pestiviruses. J Virol. 1993;67:3288-94.

19. Rumenapf $T$, Stark R, Heimann M, Thiel HJ. N-terminal protease of pestiviruses: identification of putative catalytic residues by site-directed mutagenesis. J Virol. 1998;72:2544-7.

20. Stark R, Meyers G, Rumenapf T, Thiel HJ. Processing of pestivirus polyprotein: cleavage site between autoprotease and nucleocapsid protein of classical swine fever virus. J Virol. 1993;67:7088-95. 
21. Heimann M, Roman-Sosa G, Martoglio B, Thiel HJ, Rumenapf T. Core protein of pestiviruses is processed at the $C$ terminus by signal peptide peptidase. $J$ Virol. 2006;80:1915-21.

22. Li S, Wang J, Yang Q, Naveed Anwar M, Yu S, Qiu H. Complex virus-host interactions involved in the regulation of classical swine fever virus replication: a Minireview. Viruses. 2017;9:171

23. Li W, Zhang Y, Kao CC. The classic swine fever virus (CSFV) core protein can enhance de novo-initiated RNA synthesis by the CSFV polymerase NS5B. Virus Genes. 2014;49:106-15.

24. Gladue DP, Holinka LG, Fernandez-Sainz IJ, Prarat MV, O'Donell V, Vepkhvadze N, Lu Z, Rogers K, Risatti GR, Borca MV. Effects of the interactions of classical swine fever virus Core protein with proteins of the SUMOylation pathway on virulence in swine. Virology. 2010;407:129-36.

25. Gladue DP, Holinka LG, Fernandez-Sainz IJ, Prarat MV, O'Donnell V, Vepkhvadze NG, Lu Z, Risatti GR, Borca MV. Interaction between Core protein of classical swine fever virus with cellular IQGAP1 protein appears essential for virulence in swine. Virology. 2011;412:68-74.

26. Li D, Dong H, Li S, Munir M, Chen J, Luo Y, Sun Y, Liu L, Qiu HJ. Hemoglobin subunit beta interacts with the capsid protein and antagonizes the growth of classical swine fever virus. J Virol. 2013;87:5707-17.

27. Gao L, Tu H, Shi ST, Lee KJ, Asanaka M, Hwang SB, Lai MM. Interaction with a ubiquitin-like protein enhances the ubiquitination and degradation of hepatitis C virus RNA-dependent RNA polymerase. J Virol. 2003;77:4149-59.

28. Chen J, Wu X, Chen S, Chen S, Xiang N, Chen Y, Guo D. Ubiquitin ligase Fbw7 restricts the replication of hepatitis C virus by targeting NS5B for ubiquitination and degradation. Biochem Biophys Res Commun. 2016;470: 697-703.

29. Franck N, Le Seyec J, Guguen-Guillouzo C, Erdtmann L. Hepatitis C virus NS2 protein is phosphorylated by the protein kinase CK2 and targeted for degradation to the proteasome. J Virol. 2005;79:2700-8.

30. Haqshenas $\mathrm{G}$. The $\mathrm{p} 7$ protein of hepatitis $\mathrm{C}$ virus is degraded via the proteasome-dependent pathway. Virus Res. 2013;176:211-5.

31. Aizawa S, Okamoto T, Sugiyama Y, Kouwaki T, Ito A, Suzuki T, Ono C, Fukuhara T, Yamamoto M, Okochi M, et al. TRC8-dependent degradation of hepatitis $C$ virus immature core protein regulates viral propagation and pathogenesis. Nat Commun. 2016;7:11379.

32. Pei J, Zhao M, Ye Z, Gou H, Wang J, Yi L, Dong X, Liu W, Luo Y, Liao M, Chen J. Autophagy enhances the replication of classical swine fever virus in vitro. Autophagy. 2014;10:93-110.

33. Li S, Wang J, He WR, Feng S, Li Y, Wang X, Liao Y, Qin HY, Li LF, Dong H, et al. Thioredoxin 2 is a novel E2-interacting protein that inhibits the replication of classical swine fever virus. J Virol. 2015;89:8510-24.

34. Shi BJ, Liu CC, Zhou J, Wang SQ, Gao ZC, Zhang XM, Zhou B, Chen PY. Entry of classical swine fever virus into PK-15 cells via a pH-, Dynamin-, and cholesterol-dependent, Clathrin-mediated Endocytic pathway that requires Rab5 and Rab7. J Virol. 2016;90:9194-208.

35. Riedel C, Lamp B, Heimann M, Konig M, Blome S, Moennig V, Schuttler C, Thiel HJ, Rumenapf T. The core protein of classical swine fever virus is dispensable for virus propagation in vitro. PLoS Pathog. 2012;8:e1002598.

36. Barajas D, Li Z, Nagy PD. The Nedd4-type Rsp5p ubiquitin ligase inhibits tombusvirus replication by regulating degradation of the p92 replication protein and decreasing the activity of the tombusvirus replicase. J Virol. 2009;83:11751-64

37. Ko A, Lee EW, Yeh JY, Yang MR, Oh W, Moon JS, Song J. MKRN1 induces degradation of West Nile virus capsid protein by functioning as an E3 ligase. J Virol. 2010;84:426-36.

38. Gladue DP, O'Donnell V, Fernandez-Sainz IJ, Fletcher P, Baker-Branstetter R, Holinka LG, Sanford B, Carlson J, Lu Z, Borca MV. Interaction of structural core protein of classical swine fever virus with endoplasmic reticulumassociated degradation pathway protein OS9. Virology. 2014;460-461:173-9.

39. Hüttner S, Veit C, Schoberer J, Grass J, Strasser R. Unraveling the function of Arabidopsis thaliana OS9 in the endoplasmic reticulum-associated degradation of glycoproteins. Plant Mol Biol. 2012;79:21-33.

40. Riedel C, Lamp B, Heimann M, Rumenapf T. Characterization of essential domains and plasticity of the classical swine fever virus core protein. J Virol. 2010;84:11523-31.

\section{Publisher's Note}

Springer Nature remains neutral with regard to jurisdictional claims in published maps and institutional affiliations.

\section{Ready to submit your research? Choose BMC and benefit from}

- fast, convenient online submission

- thorough peer review by experienced researchers in your field

- rapid publication on acceptance

- support for research data, including large and complex data types

- gold Open Access which fosters wider collaboration and increased citations

- maximum visibility for your research: over $100 \mathrm{M}$ website views per year

At $\mathrm{BMC}$, research is always in progress.

Learn more biomedcentral.com/submissions 